\title{
Influence of Information and Communication Technology (ICT) in Tourism Sector: A Descriptive Approach
}

Gajendra Sharma (Corresponding Author)

Department of Computer Science and Engineering, School of Engineering Kathmandu University, Dhulikhel, Kavre Email: gajendra.sharma@ku.edu.np

\section{Prakriti Dhakal}

Department of Computer Science and Engineering, School of Engineering Kathmandu University, Dhulikhel, Kavre

\author{
Article History \\ Received: April 5, 2020 \\ Revised: May 1, 2020 \\ Accepted: May 10, 2020 \\ Published: May 12, 2020 \\ Copyright (C) 2020 ARPG \\ \& Author \\ This work is licensed \\ under the Creative \\ Commons Attribution \\ International \\ (c) (1) $\mathrm{CC}$ \\ BY: Creative Commons \\ Attribution License 4.0
}

\begin{abstract}
Nepal is a country blessed with natural beauty, diverse culture, majestic Himalayas, religious destination which attracts thousands of tourists every year making the tourism industry progressive to flourish. Information Communication Technology (ICT) proves to be an effective tool for strengthening the tourism industry. Thus, the purpose of this research study is to analyze about the past scenario of tourism industry, advent of ICT in tourism industry, positive impacts of ICT in tourism industry through in-depth interview with tourism experts and people who have worked for tourism since decades. This study is a form of qualitative research where narrative inquiry has been selected and the scenario has been analyzed through themes developed from the narratives. The result reveals that the emerging technology brings positive impacts to tourism industry assisting branding, promotion of the country, enhancing networks through communication and easily booking tours. The proper utilization of ICT helps to welcome tourists and to give identity of our country Nepal to the world.
\end{abstract}

Keywords: Tourism industry; ICT; Narrative inquiry; Positive impacts; Promotion; Communication.

\section{Introduction}

Nepal, a beautiful country which is king of natural beauties, touristic, religious destinations and adventurous activities. The people, the diverse cultures, the scared Himalayas with the majestic grandeur of the sacred Himalayas, trekking mountaineering have lured visitors from all corners of the globe [1]. Along with natural beauties, touristic destinations the tourism sector is one of the driving forces of country's economy.Tourism sector is linked with the dual advantages of employment and income generation along with cultural heritage and traditionpromotions.

The Information Communication Technology (ICT) is at the peak of advancement controlling business, homes, schools and the daily lives of people. ICT provide reliable tools for strengthening tourism sector. ICT has a great impact in promoting tourism, creating opportunities, information flow to different parts of the world, tourism product marketing, and tourism related service providing facilities. In this technological era, the success of tourism depends upon utilizing the opportunity and benefits brought up by ICT.

Tourism Industry is one of the backbones of economic development in the context of our country Nepal. The growing trend of Information Communication Technology has impacted every sector in different ways. The same scenario stands for our tourism industry which is yet not identified. If there is proper identification of those positive impacts, people involved in tourism can be benefitted by maximizing positive outcomes. Henceforth, the purpose of this research is to analyze the positive impacts brought up by ICT in the progressive tourism industry of our country Nepal.

\section{Literature Review}

\subsection{ICT and Tourism Industry}

The development of ICT has affected the tourism industry; tourism industry, enterprises is utilizing the benefits of ICT innovation. Januszewska, et al. [2] published their research work entitled, "The effects of the use of ICT by tourism enterprises". This paper has shown the positive and negative impacts of ICT in tourism industry referencing the experience from Lower Silesia, one of the famous touristic destinations in Poland. The study clarifies about the benefits of on-line tourism service sales and also reveals that ICTs have great impact on running a business in travel and tourism sector, customer number are increasing, customers are satisfied and the image of company is improving. However, the challenges involving insufficient financial means, inadequate knowledge that people may have about ICT, there is lack of training regarding this matter. There is a hope shown by authors that those barriers can be minimized by initiating cooperation and participation in tourism cluster. 
ICT is a backbone of Tourism sector in our country Nepal. Shrestha and Jeong [3], carried out their research entitled "An ICT Framework of Tourists Industry of Nepal: Prospects and Challenge" where there was a framework developed from which the authors explain the respective possibilities and challenges in tourism sector of Nepal. Overall, the tourists consider Nepal as beautiful touristic destination but they complain that the accessibility and availability of communication, other required technologies are poor, internet speed is slow. The authors also mention about the proposed ICT Framework for Tourism in Nepal which will act as a provider and educator along with embedded challenges of implementation and realizations in this ICT Framework.

\subsection{ICT and Tourism Business}

There is a global transformation of tourism through ICT. In this context [4] conducted research study in "The Role ICT in Tourism Industry" which suggests about the gaps between ICT influence and tourism business, know about the view of top-level executives in tourism and suggests measures to fill the gaps in tourism enterprises. It reveals that tourism enterprises operated in traditional settings, enterprises were not been able to integrate to update latest forms of ICT tools, there was lack of awareness and training among the managers as well as working staffs about tools and technologies of ICT. However, there is personnel (like directors) agree to the urge of ICT implementation which includes ICT in online reservation, tourism financial operations, mobile communication and product distribution.

Business, ICT and Tourism are like triangles that impacts one another. Mihajlovic [5], investigated on The Impact of Information and Communication Technology (ICT) as a Key Factor of Tourism Development on the Role of Croatian Travel Agencies. This research study reveals ICTs role in strategic formation of travel agencies to understand the context of applying ICT in all business segments including travel arrangement or services and more than two third of the respondents are positive about benefits of new technologies in development of travel agencies and making communication with customers for competitiveness build up in tourism business. The tourism businessmen should utilize ICT tool to improve finance and to improve their company image. Tichaawa, et al. [6], conduct research study on "The Impacts of Information Communication Technologies (ICT) on Tourism Businesses in East London, South Africa" which expresses scenario and impact of Tourism Business from the perspective of African Country. The results showed that there was more involvement of female in tourism sector, maximum participants were found to be relatively young with average age 34 years and most of them were well-educated. This study also depicts that ICT make it possible for dissemination of information about tourism services and touristic destinations, enhances level of satisfaction of a tourist and also tourism business should incorporate ICT for profitability maximization, service enhancement and increase efficiency. Similarly, Farkhondehzadeh, et al. [7] published their research article "E-Tourism: The role of ICT in tourism industry". This paper illustrates about classification of the various type of IT-enabled enterprises and considers latest trends to support modern business strategy thus find application of those trends in tourism industry which is further supported by ICT.

\subsection{Artificial Intelligence and Tourism Industry}

The idea of Artificial Intelligent can be also applied for tourism development. The research paper "How Does Artificial Intelligence Affect the Tourism Industry?" [8] shows about relationship between Artificial Intelligence and Tourism Industry. This study tried to show chatbots a form of Artificial Intelligence used for tourism information flow, travel planning and recommends artificial intelligence can be a smart solution for tourism sector and its enhancement can be fruitful in the near future as the scope of artificial intelligence as a part of IT revolution is growing. 


\subsection{Conceptual Framework}

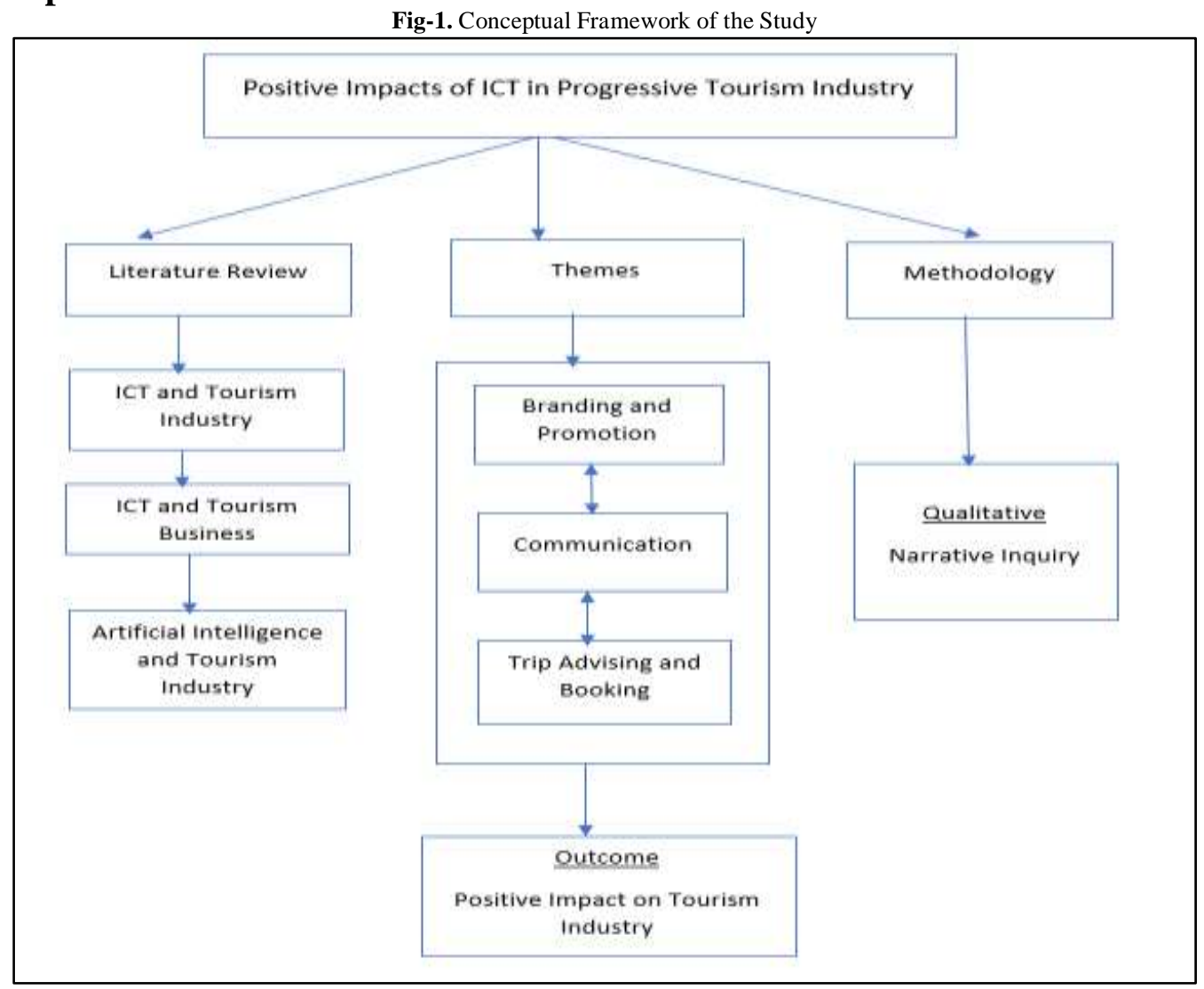

\subsection{Research Objectives}

The research objective of this paper is to analyze the past scenario of tourism industry focusing on familiarity with ICT, then about the advent of technology, its positive impact in the tourism industry from narrative inquiry of tourism entrepreneurs.

\subsection{Research Questions}

The research questions which this study aims to answer are:

- What was the scenario of tourism industry in the past without the involvement of ICT?

- What is the present condition of tourism after the involvement of ICT?

- What are the positive impacts brought up by ICT?

- What are the ways to maximize the positive benefits brought up by ICT?

\section{Methodology}

As this paper is a narrative inquiry, it reflects the qualitative research. In order to bolster any research appropriate data has to be collected. My research site was different organizations, NGO or INGO involved in promoting tourism sector of our beautiful country Nepal.From the research site I selected two tourism entrepreneurs, taking care of their ethics I have used pseudo name so as not to reveal their identity.Interview session was conducted with those two tourism entrepreneur, representing two of the leading organizations in the industry, to study in depth about the tourism industry scenario in the past without technology advancement and now in the present where technology is an integral part of everyday life and positive impacts which the technology has brought about in the tourism industry.

In the interview session, the two respondents shared their experience, scenario of their organization and tourism sector as a whole in the form of narrative. The interview was recorded with audio recording and video recording. After the collection of interview data, it was transcribed and then further analyzed in the form of themes.

\section{Analysis and Discussion}

After the generation of data, there should be analyzed properly and carefully to reach to a firm conclusion about the research study. Audio and video recording of the data was done followed by the transcription of the interview data. According to the respondents, we found both positive and negative impacts of technology on the progressive tourism industry. But positive impact outnumbers negative one as there are a lot of impacts in a positive way. Henceforth, themes were generated for the positive impacts of technology on tourism industry. The three themes that are generated are

- Branding and Promotion of Nepal

- Communication 
- $\quad$ Trip Advising and Booking

\subsection{Branding and Promotion of Nepal}

The first theme is branding and promotion of Nepal. Technology is the most effective tool to give identity of Nepal throughout the world. It helps our country Nepal to be known by people living abroad, they will get to know about the natural beauty and touristic destination of Nepal. A proper branding of Nepal can be done through technology. We can promote the beauty of our country Nepal through digital media like social networks, web portals. The information regarding touristic destination and activities of Nepal can be flowed through text, pictures, videos, photography, videography.

In this case, according to our first respondent Mr. Subedi, "Our organization is maintaining websites for the information flow about the touristic destination and services provided by the organization. When we take feedbacks from tourists they report that they got plenty of information through the website. Tourists are mostly attracted by the photos, videos of the touristic areas shared online especially in social medias." He thinks that website is the mirror of the organization for flowing required information regarding services, facilities provided to domestic as well as international tourists. Many tourists are also attracted through photography, videography of the destinations. We can promote our country Nepal by giving specific and unique brand to Nepal. Technology has also increased local tourism as well, as the sharing photos videos in social media attracts local tourist to visit different touristic destination in their own country.

Henceforth, technology provides platform for branding and promotion of our country Nepal.

\subsection{Communication}

Our next theme is communication. In the case of tourism industry, communication is also one of the essential aspects. So, technology stands out to be the best medium of communication through telephone, mobile phone, email, social networking, and messaging applications. Communication acts as a guide to tourists before planning trips, they can contact and communicate with the travel agents, tour guides to ask about the necessary details of the travel itineraries. While on the trip communication helps to ensure safety, security, risk and conflict management. If the tourists are facing any trouble or are in danger, they can immediately communicate and ask for help to the agents or the tour guides.

According to our second respondent Mr. Simkhada, "Our organization basically promotes trekking tourism. In the past there was no proper medium of communication. It was really difficult to contact tourist with tourist while booking the trip. We had to rely on the postal service. While tourists were on the trip, they used to be out of contact, many tourists, trekkers who went to mountains used to be lost and out of contact, the accidents rate were high. But now the scenario has changed, there are proper mobile networks throughout the country so the accident and missing case has become relatively low. Regular communication can be done with tourists, trekkers." The respondent is positive and satisfied with communication facilities brought up by technology. He also shared the case that last month a group of the French tourist along with Nepali tour guides who were on the ABC trekking were stuck on the way due to the ice glaciers, they were able to communicate with them on time, so the rescue team successfully reached on time for the help.

Therefore, communication facilities are enhanced through technology and tourism sector holds its benefit.

\subsection{Trip Advising and Booking}

Our last theme is trip advising and booking. The advent of technology has overcome the manual record keeping and booking system. With the utilization of technology, tourists can easily book their trips online within minutes. The trip advisors can guide tourists about the area they are visiting. Tourists can do booking according to their will and decision; they can do research and scenario analysis of area around. The concept of virtual reality has become blessing to the tourism industry. People can take a virtual tour before actually travelling the area they are interested to travel. Sitting in any corner of the world, people can visit Nepal virtually. It is possible only due to technological advancement.

In this scenario, our first respondent Mr. Subedisaid, "Booking a tour was like a headache, we have to totally rely on post office. It took minimum 35 days for any tourists to book for a tour. Tourists sent postal mail to us; we verified it and sent reply. It was so hectic and time consuming. But now, it is possible within minutes. For trip advising and booking, there are apps, tourists can book their tour through our websites as well. As the tour booking facilities become easy, we have reported rapid increase in the number of tourists, whether domestic or international, visiting Nepal. These facilities also promoted local tourism as we have witnessed many people are travelling around their own country." The respondent also shares little concept about virtual tours. In the near future, there is a work going on to involve virtual tour through their organization website. The easy tour booking facilities is luring and attracting tourists towards different touristic destinations of Nepal thereby increasing number of local and foreign tourists.

\section{Findings and Results}

Overall, it was found that technology holds positive impacts for tourism industry. Similarly, organizations, entrepreneurs are utilizing benefits of technology to promote tourism in Nepal and giving identity of Nepal in the world. If we analyze the past scenario then, manual system was used, people present written documents as a proof, postal service was used for communication. There was also problem for information flow, our respondents also said 
that they used handwritten documents, record file before, then slowly type writer was invented, then they started using computer. Now, they use technology such as digital photography, apps, and websites to provide necessary information, services, facilities. Technology has made tourism handy, nowadays tourists can book trip and know about required details staying in any corner of the world. The organization in which our respondents are attached as well as the entire tourism industry will see more development in the near future through ICT.

\section{Conclusion}

A narrative inquiry was conducted which is a part of qualitative research. The data was generated through interview and narration of the reality in which the respondents were two tourism entrepreneurs. Then the interview was transcribed and generated themes. Findings were drawn about negative as well as positive impacts introduced by rapid development and advancement of technology, however positive impacts outnumbered negative impacts. So, themes were generated for the positive impacts which are branding and promotion of Nepal, communication, trip advising and booking. In this technical era, tourism sector and organizations has become quick, fast and digital. We are able to promote our tourism of Nepal, communication reliably and efficiently with tour guides and travel agents, tourists can quickly do trip booking. The tour guides and travel agent are also in benefit as they can easily provide services to domestic as well as international tourists. We can observe that many tourists are visiting Nepal every year. The number of tourists, both local and foreign, double every year. The visit Nepal 2020 that is "Tourism Year $2020 "$ is also approaching near. Tourism Industry hopes to make "Tourism Year 2020" successful through technology.

\section{Reference}

[1] Thapa, B., 2012. Tourism in nepal: Shangri-la's troubled times. In safety and security in tourism. Routledge, pp. 124-145.

[2] Januszewska, M., Jaremen, D. E., and Nawrocka, E., 2015. "The effects of the use of ICT by tourism enterprises. ZeszytyNaukoweUniwersytetuSzczecińskiego." Scientific Journal. Service Management, vol. 16, pp. 65-73.

[3] Shrestha, D. and Jeong, S. R., 2016. "An ICT Framework for Tourism Industry of Nepal." 인터넷정보학호논문지, vol. 17, pp. 113-122.

[4] Bethapudi, A., 2013. "The role of ICT in tourism industry." Journal of Applied Economics and Business, vol. 1, pp. 67-79.

[5] Mihajlovic, I., 2012. "The impact of information and communication technology (ICT) as a key factor of tourism development on the role of Croatian travel agencies." International Journal of Business and Social Science, vol. 3, pp. 151-159.

[6] Tichaawa, T. M., Mhlanga, O., and Sicwebu, S., 2017. "The impact of information communication technologies (ICTs) on tourism businesses in East London, South Africa." Acta Universitatis Danubius. Economica, vol. 13, pp. 18-29.

[7] Farkhondehzadeh, A., Robat Karim, M. R., Roshanfekr, M., Azizi, J., and LeghaHatami, F., 2013. "ETourism: the role of ICT in tourism industry." European Online Journal of Natural and Social Sciences, vol. 2, p. 566 .

[8] Zsarnoczky, M., 2017. "How does artificial intelligence affect the tourism industry?" Management (16487974), vol. 31, pp. 85-90. 